\title{
Fantastic beasts and why to conserve them: animals, magic and biodiversity conservation
}

\author{
George Holmes, Thomas Aneurin Smith and Caroline Ward
}

\begin{abstract}
There is a broad set of human beliefs, attitudes and behaviours around the issue of magical animals, referring to both mythical animals not recognized by science and extant animals that are recognized by science but have magical properties. This is a broad issue ranging from spiritual beliefs around mythical animals living in Malagasy forests, to cultural heritage associated with the Loch Ness Monster in Scotland. Beliefs and behaviours around magical animals can have positive and negative impacts on biodiversity conservation goals. Yet, so far, the discipline of conservation biology has not adequately considered magical animals, neglecting to account for the broader knowledge from outside the natural sciences on this issue, and taking a narrow, utilitarian approach to how magical animals should be managed, without necessarily considering the broader impacts on conservation goals or ethics. Here we explore how magical animals can influence conservation goals, how conservation biology and practice has thought about magical animals, and some of the limitations of current approaches, particularly the failure to consider magical animals as part of wider systems of belief and culture. We argue that magical animals and their implications for conservation merit wider consideration.
\end{abstract}

Keywords Conservation, ethics, Madagascar, magic, snakes, spirituality, Tanzania

\section{Introduction}

\footnotetext{
T 2013 a proposed new highway in Iceland was contested 1 in court on the basis that it would cross the habitat of a valued species (The Guardian, 2013). In 2015, 350,00o tourists visited a site in Scotland primarily because it is inhabited by a rare, endemic animal (ASVA, 2016), supporting a thriving ecotourism industry. Hyaenas Crocuta crocuta in Ethiopia are tolerated because they provide vital provisioning ecosystem services that benefit local communities (Baynes-Rock, 2013). In Madagascar, in contrast, some snakes are persecuted because they provide ecosystem disservices, harmful to human health (Tingle, 2012). These are seemingly straightforward conservation stories, where human-animal

George Holmes (Corresponding author) and Caroline Ward University of Leeds, UK. E-mail g.holmes@leeds.ac.uk

Thomas Aneurin Smith University of Cardiff, UK

Received 22 December 2016. Revision requested 9 March 2017.

Accepted 30 April 2017. First published online 24 July 2017.
}

interactions produce benefits and costs for both biodiversity and people. Yet there is an often-overlooked complexity to these cases, with important implications for conservation outcomes. The species involved are either not recognized by science, or the properties of these species that local people resent or value are not recognized by science. The Icelandic protesters were protecting the habitat of Huldufólk, or elves. Ecotourists in Scotland were seeking the Loch Ness Monster Nessiteras rhombopteryx. The Ethiopian hyaenas provide the ecosystem service of eating evil spirits. The Malagasy snakes harm humans and cattle by transforming into sharp spear-like forms and dropping from trees. We argue that conservationists should take magical animals seriously, because they have important positive and negative implications for many species and habitats. Magical animals have been neglected and oversimplified within conservation, probably because of a lack of training in relevant disciplines and an overly utilitarian view of human-animal relations, and this has harmed the ability to conserve species.

We begin with a brief typology of magical and mythical animals, before outlining the complexities and diversity in beliefs on magical and mythical animals across the global South and North. We then explore how magical animals affect broader conservation goals, and how they compare to other spiritual and similar issues in conservation, followed by a critique of existing conservation literature on magic. Two case studies of magical animals, in Madagascar and Tanzania, illustrate in detail some of these trends in two countries with significant conservation activity, and the inadequacies of how conservation has approached magical animals. We conclude by exploring ways to understand the conservation implications of magical creatures.

\section{Magic, animals and contemporary human societies}

Magical animals are complex. They are found worldwide, although beliefs are locally specific and dynamic. They blur boundaries between magic, spirituality, culture, tradition and politics. We discuss here two kinds of magical animals: mythical species not recognized by science, such as the Loch Ness Monster and Icelandic elves, and extant-but-magical species that are recognized by science but have properties that are not, such as spirit-eating in hyaenas, or spear-like behaviours in snakes. This joint focus is justified for three reasons. Firstly, both are associated with protection of species and habitats in many locations, including in Western/ 
'modern'/'scientific' societies and cultures. Secondly, whereas zoologists would distinguish between mythical and extant-but-magical, local people treat them in very similar, if not identical, ways. From the perspective of studying human culture and behaviour, the divisions between when a creature is regarded as extant, mythical or as heritage can be somewhat artificial. Thirdly, both have been neglected within mainstream conservation literature. Here we define conservation as activities to preserve biological diversity and its associated values and services.

Concern for magical animals, and a broader assemblage between the spiritual and the ecological, is not confined to indigenous communities of the global South (Abrahams, 1994). Societies of the global North remain suffused with magic, spiritualism, witchcraft and the occult (Comaroff \& Comaroff, 1999). There are degrees by which individuals in all societies may hold the supposedly dissected worldviews of the scientific and the spiritual, magical or religious, evidenced by the persistence of the fantastic (including magical animals) in popular culture (Rountree, 2002), and in major and minor religions, cults and witchcrafts (Moore \& Sanders, 2001). Beliefs in magical animals are dynamic, and can transcend from the spiritual or mystical to become cultural heritage (Comaroff \& Comaroff, 1999), such as the Loch Ness Monster, Welsh dragons and the Beast of Bodmin Moor in the UK, trolls in Denmark (Karrebæk \& Maegaard, 2015), and various lake-dwelling monsters across the globe, including the Kanas Lake Monster in Xinjiang, China, the Seljordsormen in Norway, the Lagarfjót Worm in Iceland, and the Storsjöodjuret of Sweden (the latter was briefly given protected status by the Swedish Environmental Protection Agency but this was later revoked by the Swedish Parliament; Sandelin, 2014). Alongside these notable mythical creatures are more general magical associations with extant species; for example, black cats and magpies (Peltzer, 2003). Ongoing shifts are partly attributable to syncretic religions appropriating pagan, folk and indigenous worldviews around magical creatures, both historically in Europe, and ongoing in Africa, India and elsewhere (Chandran \& Hughes, 2000; Ormsby \& Bhagwat, 2010; Frascaroli, 2013). Magical animals can be powerful political tools in struggles over biodiversity and natural resources, as identity and culture associated with magical animals is re-worked as a political project. Icelandic Huldufólk are a synecdoche of the agrarian, rural, traditional past in a country that has transitioned rapidly and relatively recently into an urban, industrial, globally connected society; even recent reports of sightings of Huldufólk describe them wearing traditional farming dress rather than modern clothing. As such, arguments about defending their habitat can be more about defending ideals of past landscapes and traditions, and less about a sincere belief in the existence of elves (Hafstein, 2000). Such arguments are particularly powerful given the place of Huldufólk in Icelandic culture.
In Sikkim, India, the Lepcha people have harnessed their spiritual worldviews in an ethnic-nationalist project, (re)constructing their indigenous identity around sacred forest and species protection (Arora, 2006). By laying claim to sacred spaces and species as being under their care, particular indigenous cultures could gain access to, and control over, places and resources.

\section{Magical animals, conservation rationalities and the conservation of non-magical biodiversity}

For conservationists, interactions between humans and magical animals can be categorized according to how they benefit or harm extant biodiversity, although these categories can overlap and interact in complex ways. Firstly, some species are tolerated or encouraged because of a belief in their magical properties. In Accra, Ghana, vultures are associated with magic, and therefore harming them is considered to bring bad luck (Campbell, 2009). This leads to demonstrable differences in attitudes and behaviours towards vultures between those who hold these beliefs, and those who do not. Such beliefs are most likely to be held by older women, and least likely to be held by younger men, who tend to have a formal, western-informed education, although increasing numbers of scavengers may strengthen magical beliefs (Campbell, 2009). The spread of nationalized formal education, conversion to major religions, and heightened immigration to certain communities have all reduced the efficacy of local worldviews and associated magical creatures (Metcalfe et al., 2010), although witchcraft and spiritualism appear to be rising in modern Africa (Kohnert, 2003). The survival of large predators outside protected areas depends on their acceptance or tolerance by local communities, forged by place-specific circumstances in which spiritual beliefs may play a key part (Pooley et al., 2017). In Kombolcha, Ethiopia, hyaenas are tolerated and encouraged, despite many instances of hyaena attacks on humans, particularly children. Hyaenas are believed to bring supernatural messages through their howls, eat evil spirits, and thus protect local people. These beliefs coexist alongside recognition of more conventional ecosystem services provided by hyaenas, such as predation on crop-raiding herbivores, and collectively these underpin attitudes towards hyaenas (Baynes-Rock, 2013). Local beliefs in the magical properties of hyaenas pre-date Islam, and survive only because of the incompleteness of people's conversion to Islam. In some areas of Brazil, a belief that dolphins can magically transform into people underpins local attitudes and behaviour, and ultimately the conservation of dolphins in these places (Alves \& Rosa, 2008), although, as explored below, closely related beliefs have also led to negative outcomes for dolphins. Magical animals can act as umbrella species, whose conservation benefits and protects 
other species occupying the same habitat, as with the Huldufólk.

In other instances, beliefs in magical animals are incidental to conservation goals. Some groups in the Serengeti, Tanzania, consider certain animals to be sacred totems, with spiritual connections to these groups. Hunting of these animals should follow specific procedures and rituals to prevent bad luck. Such beliefs prevent some groups from poaching elephants for ivory, but are not sufficiently widespread to have a significant impact (Kideghesho, 2008; Kaufmann, 2014). In East Africa, such beliefs have been weakened by decades of colonial and postcolonial suppression of traditional spiritual activities, and the spread of Christianity.

A belief in the magical properties of animals can impede their conservation, and magical animals are sometimes actively persecuted, such as aye-ayes Daubentonia madagascariensis in Madagascar, and Caribbean owls. Such beliefs are rarely considered within literature on human-wildlife conflict. In other cases, a belief that certain species possess magical properties can lead to unsustainable rates of harvesting (e.g. of dolphins and several species of reptiles in some areas of Brazil; Alves \& Rosa, 2008; Alves et al., 2009). Conservationists propose solutions such as captive breeding and promotion of alternative, sustainable, magical products. Persecution or harvesting rates of extant-butmagical animals may increase with increased access to better technology, or integration of communities into commodity chains (Dickman et al., 2015). Impediments to conservation can also be less direct; e.g. in some parts of Papua New Guinea, communities argue that some species will never become extinct because the local people know magic spells to make the species return to that area (Bastyte et al., 2011).

Although magical animals rarely feature in the conservation literature, there are other parallel issues that feature more prominently. A focus on magical animals both extends and illuminates problems within this literature. Firstly, there is research on religion and conservation, such as that associated with the Religion and Conservation Biology Working Group of the Society for Conservation Biology. This focuses largely on established mainstream religions, and on broad interactions between environmental ethics and religious beliefs (e.g. McDaniel, 2002). Here we focus instead on relatively marginal religious beliefs, on particular species rather than broad attitudes, and on instances where spiritual or magical beliefs have transformed into cultural heritage, yet still exert an influence on human behaviour and on conservation outcomes, a blurrier definition of spiritual dimensions of nature.

Secondly, there is substantial work on sacred sites and other culturally and spiritually protected areas set aside from resource use, which are increasingly recognized for their contribution to conservation (Anthwal et al., 2010;
Ormsby \& Bhagwat, 2010). Sacred sites are relatively straightforward for conservationists to comprehend: as defined territories with norms and rules of resource (non) use, they closely resemble other forms of protected areas and can be included in IUCN definitions and databases of protected areas (Borrini-Feyerabend et al., 2004). Sacred sites are often analysed using concepts and approaches typically used for understanding protected areas and common pool resources. This overlooks the complexities of the spiritual beliefs underpinning these areas, their past evolution and possible future directions, and implies that such sites owe their existence to a conservation ethic, not a spiritual one (Salick et al., 2007; Kibet, 2011). The literature emphasizes the positive contribution of sacred sites to conservation, rather than their negative consequences. In contrast, magical animals are less easy for conservationists to conceptualize using dominant conservation concepts. We focus on the positive and negative implications of magical animals for conservation, and on the rationalities and beliefs underpinning human relations with magical animals, in order to understand their dynamics and possible futures.

Thirdly, there is a smaller body of literature on the implications of taboos (customary prohibitions on resource use) for conservation (Virtanen, 2002). As with sacred sites, this literature understands taboos using institutional approaches typically used for conceptualizing common pool resources, and tends to assume such resources are protected by a conservation ethic, not a spiritual one (Byers et al., 2001; Kideghesho, 2009). It also focuses on taboos within traditional societies (typically meaning indigenous groups in the global South), rather than the diversity of societies represented within cases of magical animals. Where this literature does consider sacred sites in the global North, it focuses largely on forest sites and their past religious significance rather than contemporary society (Chandran \& Hughes, 2000; Frascaroli, 2013). Literature on taboos focuses, by definition, on instances of non-use of resources, whereas our focus goes beyond this to include wider relations with magical and spiritual aspects of nature, antagonism between people and nature, and persecution of biodiversity.

Studying magical animals has the potential to strengthen and broaden the literature on spiritual aspects of biodiversity conservation, yet several problems regarding how conservation has previously conceptualized spirituality and magical animals need to be addressed. Firstly, conservation is primarily about 'modifying human actions to minimize their negative impacts upon biodiversity' (St John et al., 2013, p. 344), yet within conservation, people are mostly regarded as rational decision makers, or Homo economicus. This means spiritual and magical beliefs, which are perceived as irrational, are often absent from conservationists' understanding of threats to biodiversity, such as humanwildlife conflict. For example, research on human-predator conflicts in the Caribbean (e.g. Turvey et al., 2014) has 
viewed persecution of owls and mongooses through the lens of rationality, even though mongoose persecution is an economically rational response to predation of chickens, whereas owls are persecuted because they are considered to be evil spirits in many branches of syncretic vodou (Wiley, 1985). The natural science bias of conservation often leads to an approach in which emotion is considered to be anathema to rational decision making (Nelson et al., 2016). Secondly, relatively few conservationists have been trained in social science or humanities disciplines that deal with irrational aspects of human beliefs and behaviours, despite the many calls for an interdisciplinary conservation science that values methods and inputs from outside the natural sciences (St John et al., 2013; Bennett et al., 2017). In this context the expanding literature on the environmental humanities, rarely explored by conservation, is relevant (Sörlin, 2012). Magical animals have been examined by disciplines such as ethnoecology (Alves, 2012), environmental history (Pooley, 2016), and social anthropology (e.g. Knight, 2000). This literature is too complex to summarize here, but it yields detailed, place-based explorations of people and their relationships with biodiversity, focusing on what makes sense to local people rather than to scientific conservationists, keenly attuned to uncovering the often hidden details and rationales behind human behaviour through qualitative methods such as ethnography.

Thirdly, combining the previous two points, with few exceptions (e.g. Dickman et al., 2015; Aisher \& Damodaran, 2016; Pooley et al., 2017) the conservation literature has given inadequate treatment to the complex social and cultural context, or the ontological system, in which magical animals are situated. Conservation may have an overly simplistic view of how to manage magical beliefs, promoting those seen as beneficial to conservation and repressing those that are not (Colding \& Folke, 2001; Kibet, 2011). This utilitarian view isolates beliefs in magical animals from other forms of belief and knowledge, rather than seeing them as part of a broader, complex, dynamic worldview. For example, the literature on sacred sites and resource taboos tends to rationalize their protection by local societies either as providers of local ecosystem services (it is rational to consider spaces as sacred, therefore requiring conservation, because they provide direct ecosystem service benefits), or because worship or persecution of magical creatures plays an important role in maintaining the associated social system, the logic being it is rational to promote social integrity around cultural rituals and norms (Anthwal et al., 2010; Rutte, 2011). This contrasts with the vast humanities literature exploring societies and their worldviews around magic, witchcraft and spiritualities in depth. This complex literature identifies how beliefs in magic are part of broader rationalities, and explores their role in social, cultural and political life. For example, magical animals may be considered alongside scientific explanations in people's understandings of phenomena (Stambach, 200o). In South Africa and Tanzania witchcraft has been recognized by the state through law, and through state practices that officialize witch-finding (Kohnert, 2003; Mesaki, 2009). Occult practices that harness the harmful properties of magical creatures, such as witches using snakes to attack their victims (Bjerke, 1969), can have negative effects on the social fabric of local societies (Eves \& Forsyth, 2015).

Yet instead of seeing magic and spirituality as part of a broader system, conservation interventions have tended to pick out individual aspects of beliefs or culture to either strengthen (if considered pro-conservation) or weaken and change (if considered anti-conservation). These simplistic practices lack attention to local realities, nullifying the rhetoric behind local and participatory forms of conservation (Verschuuren, 2006; Dudley et al., 2009). Treating spiritual worldviews on magical animals as forms of environmental management, without considering the broader system in which these aspects occur, can cause problems and can backfire; for example, attempts to officialize sacred landscapes in Australia and Canada for conservation management have problematically fixed boundaries around previously fluid sacred areas (Byers et al., 2001; Schie \& Haider, 2015). Changing values also requires changes in the broader structures and societies in which those values are embedded (Manfredo et al., 2016). Alternatively, promoting or manipulating conservation-friendly spiritual beliefs can undermine science-based conservation activities (Dickman et al., 2015).

Promoting or suppressing individual aspects of beliefs or culture can have unforeseen long-term consequences for human well-being and culture as well as biodiversity (Dickman et al., 2015). There is an ethical conundrum in conservationists' utilitarian approach of promoting those aspects of culture and belief that benefit conservation goals whilst suppressing those that don't. Conservationists are fearful of accusations of cultural imperialism when criticizing the spiritual and cultural practices that are harmful to biodiversity, particularly in the global South (Dickman et al., 2015). A broader debate on how conservation treats cultural practices is required. The following sections highlight the issues around magical animals in two countries of high conservation value: Madagascar and Tanzania.

\section{Madagascar}

Beliefs surrounding magical and mythical animals in Madagascar are often interlinked with local fadys, a system of informal institutions making certain behaviours taboo, which is a strong part of Malagasy culture. Breaking fadys risks supernatural retribution, affecting individuals or leading to wider consequences (Scales, 2012). Fadys can be highly localized and may differ between neighbouring villages. 
Many lemur species are believed to be the spirits of Malagasy ancestors, and therefore it is fady to kill these species (Jones et al., 2008). Other species, such as the aye-aye, are associated with negative beliefs. The aye-aye is considered to be a harbinger of evil, its appearance predicting death or sickness in the village. The Malagasy expression 'Mangatabmo hita, miseho tsy tsara' translates as 'If (the aye-aye) is seen, there will be evil' (Simons \& Meyers, 2001). Another belief is that aye-ayes sneak into houses and use their long middle fingers to murder the sleeping occupants by puncturing their aortas (Goodman, 2015). To prevent bad luck, the aye-aye must be killed and displayed on roadside poles. On occasions entire villages have been abandoned after an aye-aye sighting (Simons \& Meyers, 2001; Goodman, 2015).

Reptiles are also linked to magical or spiritual beliefs. The zebu killing snake or fandrefiala (genus Ithycyphus) is believed to be able to straighten its body into a spear, dropping out of trees and killing people and livestock. Its characteristic red tail is said to be caused by bloodstains (Tingle, 2012).

The kalanoro are 'beneficent spirits that often inhabit rivers or caves; they tend to be envisioned as women with very long hair and fingernails who eat crabs, have reversed feet (heels in front, toes in the back), and are very short like dwarves' (Golden \& Comaroff, 2015a, p. 4). Belief in their existence is widespread throughout Madagascar, although explanations of their role vary, from kidnapping children, luring people into getting lost in the forest, advising on medicinal plants and herbs, or dictating fadys to individuals through visions or dreams (Hobbs, 2001; Mattheeuws, 2008; Golden \& Comaroff, 2015b). It is believed the kalanoro disappear from the forest if it is destroyed or degraded (Golden \& Comaroff, 2015a).

Fadys can protect particular species (Lingard et al., 2003; Randrianandrianina et al., 2010), and are often promoted as exemplifying how conservation can align with tradition, following calls for integration of traditional knowledge, practices and beliefs within conservation (e.g. Infield \& Mugisha, 2013). The historically low prevalence of bushmeat hunting in Madagascar, compared to other tropical countries, has been linked to fadys, as fady species are eaten less frequently (Jones et al., 2008; Jenkins et al., 2011). Fadys have been promoted to prevent extinction of the Critically Endangered radiated tortoise Geochelone radiata (Nussbaum \& Raxworthy, 2000). In one conservation project, villages with strong fadys protecting tortoises were rewarded with school buildings, in the hope this would encourage neighbouring villages to strengthen their cultural beliefs (Lingard et al., 2003; Hudson, 2013).

However, an assumption that beliefs are and will always be conservation-friendly risks oversimplification. 'Malagasy taboos are directed at something very different from conservation: namely, at pursuing a structured relationship with their ancestors' (Kaufmann, 2014, p. 329). Although fadys are more strictly adhered to than wildlife protection laws, they are too heterogeneous between and within communities to provide any real protection (Golden \& Comaroff, 2015b). The radiated tortoise fady illustrates the dangers of misinterpreting behaviours related to beliefs; local people would not harm tortoises, for fear of spiritual retribution, but they would not stop outsiders from harming or removing tortoises 'since it did not involve anybody bound by a rule that forbade harming the animals' (Kaufmann, 2014, p. 328). Rapid immigration, economic development, failed harvests or high levels of poverty and malnutrition may weaken adherence to fadys (Jones et al., 2008; Jenkins et al., 2011; Kaufmann, 2014). Concern that fadys may be eroding, or do not protect species as hoped, has led to calls for increased enforcement of wildlife laws (e.g. Jenkins et al., 2011). However, this highlights a false assumption that culture remains static throughout time, whereas beliefs may be fluid and can erode, strengthen or evolve (Golden \& Comaroff, 2015b). Uptake of Western religions, such as Christianity, does not appear to have affected belief and adherence to fadys, despite potential conflicts (Golden \& Comaroff, 2015a).

Fadys and other beliefs can also have negative conservation impacts. Fady-related killing of aye-ayes is considered a key threat to their survival (Andriaholinirina et al., 2014). Negative fadys linked to snakes and chameleons have not been studied in depth, but could also represent a threat to certain species. In these cases, beliefs are considered to be an obstacle to conservation efforts, and education a solution to remove these irrational perceptions; for example, Glaw et al. (2008) in reference to the aye-aye: 'More efforts to sensitize the natives for the protection... would be desirable to reduce the threatening of this exceptional primate species'. This response contradicts calls to integrate traditional practices and beliefs into conservation, and the ethics of this selectivity regarding cultural beliefs has been questioned (Dickman et al., 2015). Keller (2009) stated: 'If only things such as fady and 'sacred forests' are promoted as valuable 'culture' in the conservation literature, this may give rise to the suspicion that what we are really dealing with is an unsettling attempt to use 'culture' simply in order to better sell to the Malagasy what they might, in fact, not want.'

\section{Tanzania}

Snakes have symbolic importance across diverse cultures. In some, snakes are worshipped and revered, whereas others, particularly those influenced by monotheistic religions such as Christianity, regard snakes as materializations of Satan (Sunseri, 1999). Across Africa, snakes are commonly considered to be magical creatures (Bjerke, 1969; Sunseri, 1999). Although literature on sacred sites has supposed connections between the sanctity of species and habitats and 
their ecosystem service benefits for local people (Salick et al., 2007; Kibet, 2011), the snake as a magical creature challenges this. Snakes are not easily recognizable to humans as ecologically beneficial, are often regarded as dangerous and, as magical creatures, may be regarded as good or evil. In East Africa, encounters between snakes and people are common (Nonga \& Haruna, 2015), and can be dangerous for both sides. Snakebites are an important cause of morbidity and mortality among rural dwellers (Maregesi et al., 2013), and encounters may cause psychological harm. Yet coexistence between snakes and people can bring mutual benefits; for example, snakes kill unwanted insects and rodents, and people may take measures to preserve snake habitats.

In Tanzania snakes are worshipped and protected as ancestral spirits, and persecuted and killed as embodiments of evil and ancillaries to witchcraft killings. The diversity of the magical properties attributed to snakes is partly a result of Tanzania's ethnic diversity, with 120 tribes. Tribes typically have their own languages, sets of worldviews and cultural traditions, and inhabit diverse geophysical, climatic and ecological areas (Kideghesho, 2009); within tribes there is further diversity between clans and villages. Despite this diversity there is some commonality. Many tribes have sacred natural sites, typically forests, such that across diverse rural areas sacred and ritual sites are significant as habitats for species, including endemic or threatened species (Mgumia \& Oba, 2003; Smith, 2017). It is also typical for ethnic/tribal groups to regard species of animals and plants as spiritually significant, although there is considerable diversity in these beliefs (Kideghesho, 2009).

There is limited research on the magical properties of snakes in Tanzania and the consequences for conservation. In Monduli District, in the north of the country, with a significant Maasai population, there are reports of frequent snake killing because it is believed that snakes are evil and cause misfortune, and they are associated with witchcraft (Nonga \& Haruna, 2015). Conversely, for the Zaramo of coastal Tanzania, snakes can be the personification of the god Koleo, who, in one oral tradition, appears to women as a snake and asks for them to marry him (Sunseri, 1999). For other ethnic groups in north-western Tanzania, species of snakes, including pythons, puff adders, the black mamba and cobras, are associated with specific clans as their animal symbol, which affords protection (Kideghesho, 2008, 2009). For the Zinza, snakes are both ancestor spirits and evil spirits, to be protected or killed accordingly (Bjerke, 1969).

In 2015 TAS conducted research across six villages in Mbozi District, western Tanzania that were traditionally those of the Nyiha people, although most are now ethnically plural. Each village has its own sacred natural sites, mostly forests, containing the burial grounds of previous chiefs. The living chief (abamwene) and his assistants have powers to contact ancestral spirits inhabiting forests, who often appear as snakes. Intruders from other villages have found snakes in their pockets during negotiations about forest ownership, and local trespassers have found snakes on their buckets. Pythons are believed to embody the spirits of dead chiefs, which are contacted by living chiefs and elders concerned about intruders or other wrongdoings. According to local chiefs, 'the python is the owner of the site... the one protecting it. . people fear that if they clear the site, the python will migrate to another area... [and] the area will face difficulties with rainfall.' It is in the interests of local people to maintain the habitat of the python to keep the spirits of their ancestors accessible to the living chief. The python-chief also serves as a conduit to other gods, to pray for rainfall or other matters affecting the village. However, this constellation of beliefs is under pressure. Politically, chieftainship was abolished by the postindependence government in 1961, and replaced by elected village officials. Chiefs retain a spiritual role, yet this too is undermined by Christianization and incomers from other tribes who do not share Nyiha worldviews, a situation common in western Tanzania (Smith, 2017).

Studies of snakes as magical creatures often follow a utilitarian approach, recommending local people should be educated to learn the importance of snakes for habitats (if worldviews regard snakes as evil), or conversely that taboos protecting snakes need to be reinforced and enforced by some external body, typically the state (Colding \& Folke, 2001; Kideghesho, 2009). These conceptualizations of snake-protection understand these worldviews as emic supernatural beliefs that reinforce taboos, or automatic sanctions (Colding \& Folke, 2001). For others they are invisible systems of local resource management' (Kideghesho, 2008), offering a way in for conservationists to appropriate local worldviews (Kideghesho, 2009). More in-depth anthropological and sociological studies recognize that the meaning and purpose of magical creatures have changed and are changing. For the Zinza, Bjerke (1969) reported in the 1960 os that the beneficial beliefs associated with some spirits were rapidly disappearing, such that they were viewed as demonic beings. A number of studies (e.g. Bjerke, 1969; Sunseri, 1999) claim Christianization has contributed to the perception of once benign or beneficial spiritual creatures as evil, or that Abrahamic traditions have replaced mystical ties between snakes and sexuality, and fertility and rainfall, with satanic associations.

To suggest that snakes as mystical creatures are of value to the species conservation ethos is simplistic at best, and contradictory at worst. Studies of traditional knowledge, sacred natural sites and conservation (Ormsby \& Bhagwat, 2010; Blicharska \& Mikusiński, 2014) typically ignore the complexities within cultural groups and across diverse groups within states. In the case of the Nyiha in Mbozi, suggestions by some that traditional institutions, in this case local chiefs, should be empowered to enforce local 
regulations (Kideghesho, 2009) are politically sensitive given that the state has deliberately shifted power away from hereditary chiefs to democratically elected village governments. To give chiefs official spiritual authority would undoubtedly anger those who do not adhere to traditional worldviews, and giving them powers over forest protection would undermine local village governments. Snakes are ambiguous and complex magical creatures, both good and evil in various geographical, ethnic and spiritual contexts, and to entangle them with existing conservation management would be equally complex.

\section{Conclusions}

We have illustrated that magical animals can have positive and negative consequences for conservation, and that the relationship between magical animals, human beliefs and behaviour, and extant biodiversity is complex. We have also shown that current views of magical animals within conservation are inadequate. Beliefs in magical animals are often ignored, and when acknowledged they are often treated as isolated issues to be tackled individually based on their direct impact on conservation goals, rather than considered as part of a complex system or worldview. In response, we argue that conservation needs to interrogate the interaction of magical animals, extant animals and biodiversity conservation goals. It should consider the breadth of magical animals, from those that are mainly spiritual to those such as the Huldufólk or Loch Ness Monster, which are becoming, or have become, more political or cultural in nature, recognizing the blurred boundaries around such categories. It should see these animals as part of broader systems, be it of cultures, rationalities or belief systems, and acknowledge that beliefs and values around magical animals are dynamic. Such an endeavour would require disciplines beyond natural sciences, including anthropology, ethnozoology, history, theology and others. It would require scientifically trained conservationists to engage with new methodologies, particularly those involving long-term studies and qualitative data, which generate locally specific understandings rather than universal theories, and that embrace human irrationality. Here approaches such as multispecies ethnography, which studies the entanglements of human and nonhuman life, could be useful. Multispecies ethnography can combine ethological studies of animal behaviour with ethnographic studies of human behaviour, values, culture and beliefs, combining the material and the social, often grounded in locally specific human-animal relations (Aisher \& Damodaran, 2016; Pooley et al., 2017). As such, it is well placed to understand the complexities of interactions between humans, extant and magical biodiversity (e.g. Baynes-Rock, 2013). Ultimately, by understanding human interactions with magical animals, conservation could create successful coexistence between humans and non-humans.

\section{Acknowledgements}

We thank Guðni Th. Jóhannesson and Alaric Hall for their insights into Huldufólk and Icelandic culture and politics, and William Andindilile for his assistance with fieldwork in Tanzania. CW's contribution was supported by the Natural Environment Research Council.

\section{Author contributions}

The research was conceived by GH. GH and TAS led the writing of the main sections of the article. TAS wrote the Tanzania section, CW the Madagascar section. All authors contributed to refining and editing the text.

\section{References}

Abrahams, R.G. (ed.) (1994) Witchcraft in Contemporary Tanzania. Cambridge University Press, Cambridge, UK.

Aisher, A. \& Damodaran, V. (2016) Introduction: human-nature interactions through a multispecies lens. Conservation \& Society, 14, 293-304.

Alves, R.R. (2012) Relationships between fauna and people and the role of ethnozoology in animal conservation. Ethnobiology and Conservation, 1, 1-69.

Alves, R.R., Neto, N.A.L., Santana, G.G., Vieira, W.L. \& Almeida, W.O. (2009) Reptiles used for medicinal and magic religious purposes in Brazil. Applied Herpetology, 6, 257-274.

Alves, R.R. \& RosA, I.L. (2008) Use of tucuxi dolphin Sotalia fluviatilis for medicinal and magic/religious purposes in north of Brazil. Human Ecology, 36, 443-447.

Andriaholinirina, N., Baden, A., Blanco, M., Chikhi, L., Cooke, A., Davies, N. et al. (2014) Daubentonia madagascariensis. In The IUCN Red List of Threatened Species 2014: e.T6302A16114609. Http://dx.doi.org/10.2305/IUCN.UK.2014-1.RLTS.T6302A16114609. en [accessed 1 June 2017].

Anthwal, A., Gupta, N., Sharma, A., Anthwal, S. \& Kim, K.-H. (2010) Conserving biodiversity though traditional beliefs in sacred groves in Uttarakhand Himalaya, India. Resources, Conservation and Recycling, 54, 962-971.

Arora, V. (2006) The forest of symbols embodied in the Tholung sacred landscape of North Sikkim, India. Conservation \& Society, 4 $55-83$.

ASVA (Association of Scottish Visitor Attractions) (2016) Visitor Trends Report. ASVA, Edinburgh, UK.

Bastyte, D., Fox, J.C. \& Anthony, B.P. (2011) Assessing the importance of local biodiversity to communities in Madang province, Papua New Guinea. In Native Forest Management in Papua New Guinea: Advances in Assessment, Modelling and Decision-Making (eds J.C. Fox, R.J. Keenan, C.L. Brack \& S. Saulei), pp. 53-68. ACIAR Proceedings No. 135. Australian Centre for International Agricultural Research, Canberra, Australia.

BAYNES-Rock, M. (2013) Local tolerance of hyena attacks in East Hararge Region, Ethiopia. Anthrozoös, 26, 421-433. 
Bennett, N.J., Roth, R., Klain, S.C., Chan, K.M.A., Clark, D.A., Cullman, G. et al. (2017) Mainstreaming the social sciences in conservation. Conservation Biology, 31, 56-66.

BJERKe, S. (1969) The high god among the Zinza of northwestern Tanzania. Numen, 16, 186-210.

Blicharska, M. \& Mikusiński, G. (2014) Incorporating social and cultural significance of large old trees in conservation policy. Conservation Biology, 28, 1558-1567.

Borrini-Feyerabend, G., Kothari, A. \& Oviedo, G. (2004) Indigenous and Local Communities and Protected Areas: Towards Equity and Enhanced Conservation. IUCN, Gland, Switzerland, and Cambridge, UK.

Byers, B.A., Cunliffe, R.N. \& Hudak, A.T. (2001) Linking the conservation of culture and nature: a case study of sacred forests in Zimbabwe. Human Ecology, 29, 187-218.

CAmpbell, M. (2009) Factors for the presence of avian scavengers in Accra and Kumasi, Ghana. Area, 41, 341-349.

Chandran, M.D.S. \& Hughes, J.D. (2000) Sacred groves and conservation: the comparative history of traditional reserves in the Mediterranean area and in south India. Environment and History, 6, 169-186.

Colding, J. \& Folke, C. (2001) Social taboos: 'invisible' systems of local resource management and biological conservation. Ecological Applications, 11, 584-600.

Comaroff, J. \& Comaroff, J.L. (1999) Occult economies and the violence of abstraction: notes from the South African postcolony. American Ethnologist, 26, 279-303.

Dickman, A., Johnson, P.J., van Kesteren, F. \& Macdonald, D.W. (2015) The moral basis for conservation: how is it affected by culture? Frontiers in Ecology and the Environment, 13, 325-331.

Dudley, N., Higgins-Zogib, L. \& Mansourian, S. (2009) The links between protected areas, faiths, and sacred natural sites. Conservation Biology, 23, 568-577.

Eves, R. \& Forsyth, M. (2015) Developing insecurity: sorcery, witchcraft and Melanesian economic development. State, Society and Governance in Melanesia Discussion Paper, Australian National University, Canberra, Australia.

Frascaroli, F. (2013) Catholicism and conservation: the potential of sacred natural sites for biodiversity management in central Italy. Human Ecology, 41, 587-601.

Glaw, F., Vences, M. \& Randrianiania, R.D. (2008) Killed aye-aye (Daubentonia madagascariensis) exposed on the gallows in northeastern Madagascar. Lemur News, 13, 6-7.

Golden, C.D. \& Comaroff, J. (2015a) Effects of social change on wildlife consumption taboos in northeastern Madagascar. Ecology and Society, 20, http://dx.doi.org/10.5751/ES-07589-200241.

Golden, C.D. \& Comaroff, J. (2015b) The human health and conservation relevance of food taboos in northeastern Madagascar. Ecology and Society, 20, http://dx.doi.org/10.5751/ ES-07590-200242.

Goodman, S.M. (2015) Remains of an aye-aye (Daubentonia madagascariensis) at the edge of the Parc National d'Ankarana, Région Diana. Malagasy Nature, 9, 107-108.

HafsteIn, V.T. (2000) The elves' point of view: cultural identity in contemporary Icelandic elf-tradition. Fabula, 41, 87.

Hоввs, J.J. (2001) People and caves in Madagascar. Focus on Geography, 46, 1-7.

Hudson, R. (2013) Troubled times for the radiated tortoise (Astrochelys radiata). In Turtles on the Brink in Madagascar: Proceedings of Two Workshops on the Status, Conservation, and Biology of Malagasy Tortoises and Freshwater Turtles. Chelonian Research Monographs, 6, 67-74.

Infield, M. \& Mugisha, A. (2013) Culture, Values and Conservation: A Review of Perspectives, Policies and Practices for the Integration of
Cultural and Ethical Values into Conservation. Fauna \& Flora International, Cambridge, UK.

Jenkins, R.K., Keane, A., Rakotoarivelo, A.R.,

Rakotomboavonjy, V., Randrianandrianina, F.H., RazafimanahaKa, H.J. et al. (2011) Analysis of patterns of bushmeat consumption reveals extensive exploitation of protected species in eastern Madagascar. PLoS ONE, 6(12), e27570.

Jones, J.P., Andriamarovololona, M.M. \& Hockley, N. (2008) The importance of taboos and social norms to conservation in Madagascar. Conservation Biology, 22, 976-986.

KarrebeK, M.S. \& Maegaard, M. (2015) Pigs, herring and Bornholm on a table: a high-end restaurant's construction of authenticity. Tilburg Papers in Culture Studies, Tilburg University, Tilburg, Netherlands.

KAUfMAnN, J.C. (2014) Contrasting visions of nature and landscapes. In Conservation and Environmental Management in Madagascar (ed. I.R. Scales), pp. 320-341. Routledge, London, UK.

Keller, E. (2009) The danger of misunderstanding 'culture'. Madagascar Conservation \& Development, 4, 82-85.

Kibet, S. (2011) Plant communities, species diversity, richness, and regeneration of a traditionally managed coastal forest, Kenya. Forest Ecology and Management, 261, 949-957.

Kideghesho, J.R. (2008) Co-existence between the traditional societies and wildlife in western Serengeti, Tanzania: its relevancy in contemporary wildlife conservation efforts. Biodiversity and Conservation, 17, 1861-1881.

Kideghesho, J.R. (2009) The potentials of traditional African cultural practices in mitigating overexploitation of wildlife species and habitat loss: experience of Tanzania. International Journal of Biodiversity Science \& Management, 5, 83-94.

Knight, J. (ed.) (200o) Natural Enemies: People-Wildlife Conflicts in Anthropological Perspective. Routledge, London, UK.

Kohnert, D. (2003) Witchcraft and transnational social spaces: witchcraft violence, reconciliation and development in South Africa's transition process. The Journal of Modern African Studies, $41,217-245$.

Lingard, M., Raharison, N., Rabakonandrianina, E., Rakotoarisoa, J.A. \& ElmQvist, T. (2003) The role of local taboos in conservation and management of species: the radiated tortoise in southern Madagascar. Conservation \& Society, 1, 223-246.

Manfredo, M.J., Teel, T.L. \& Dietsch, A.M. (2016) Implications of human value shift and persistence for biodiversity conservation. Conservation Biology, 30, 287-296.

Maregesi, S., Kagashe, G. \& Masatu, K. (2013) Ethnopharmacological survey of snake bite treatment in Ukerewe Island, Tanzania. Scholars Academic Journal of Pharmacy, 2, $381-386$.

Mattheeuws, C. (2008) Towards an anthropology in life: the astrological architecture of Zanadroandrena Land, West Bezanozano, Central East Madagascar. PhD thesis. University of Aberdeen, Aberdeen, UK

MCDAniel, J. (2002) Spirituality and sustainability. Conservation Biology, 16, 1461-1464.

MesaKi, S. (2009) Witchcraft and the law in Tanzania. International Journal of Sociology and Anthropology, 1, 132-138.

Metcalfe, K., Ffrench-Constant, R. \& Gordon, I. (2010) Sacred sites as hotspots for biodiversity: the Three Sisters Cave complex in coastal Kenya. Oryx, 44, 118-123.

Mgumia, F.H. \& Ова, G. (2003) Potential role of sacred groves in biodiversity conservation in Tanzania. Environmental Conservation, $30,259-265$.

Moore, H.L. \& SAnders, T. (eds) (2001) Magical Interpretations, Material Realities: Modernity, Witchcraft and the Occult in Postcolonial Africa. Routledge, London, UK. 
Nelson, M.P., Bruskotter, J.T., Vucetich, J.A. \& Chapron, G. (2016) Emotions and the ethics of consequence in conservation decisions: lessons from Cecil the Lion. Conservation Letters, 9, 302-306.

Nonga, H.E. \& Haruna, A. (2015) Assessment of human-snake interaction and its outcomes in Monduli District, northern Tanzania. Tanzania Journal of Health Research, 17, 1-12.

Nussbaum, R.A. \& Raxworthy, C.J. (200o) Commentary on conservation of 'Sokatra' the radiated tortoise (Geochelone radiata) of Madagascar. Amphibian and Reptile Conservation, 2, 6-14.

Ormsiy, A.A. \& BhaGWAT, S.A. (2010) Sacred forests of India: a strong tradition of community-based natural resource management. Environmental Conservation, 37, 320-326.

Peltzer, K. (2003) Magical thinking and paranormal beliefs among secondary and university students in South Africa. Personality and Individual Differences, 35, 1419-1426.

Pooley, S. (2016) A cultural herpetology of Nile crocodiles in Africa. Conservation \& Society, 14, 391-405.

Pooley, S., Barua, M., Beinart, W., Dickman, A., Holmes, G., LORIMER, J. et al. (2017). An interdisciplinary review of current and future approaches to improving human-predator relations. Conservation Biology, 31, 513-523.

Randrianandrianina, F.H., Racey, P.A. \& Jenkins, R.K.B. (2010) Hunting and consumption of mammals and birds by people in urban areas of western Madagascar. Oryx, 44, 411-415.

Rountree, K. (2002) How magic works: New Zealand feminist witches' theories of ritual action. Anthropology of Consciousness, 13, $42-59$.

Rutte, C. (2011) The sacred commons: conflicts and solutions of resource management in sacred natural sites. Biological Conservation, 144, 2387-2394.

Salick, J., Amend, A., Anderson, D., Hoffmeister, K., Gunn, B. \& Zhendong, F. (2007) Tibetan sacred sites conserve old growth trees and cover in the eastern Himalayas. Biodiversity and Conservation, 16, 693-706.

SANDELIN, E. (2014) Eating E.T. In Exploring Human-Animal Relations in Science, Society and Culture (eds E. Andersson Cederholm, A. Björck, K. Jennbert \& A-S. Lönngren), pp. 47-57. The Pufendorf Institute of Advanced Studies, Lund University, Lund, Sweden.

SCALES, I.R. (2012) Lost in translation: conflicting views of deforestation, land use and identity in western Madagascar. The Geographical Journal, 178, 67-79.

Schie, R.V. \& HAider, W. (2015) Indigenous-based approaches to territorial conservation: a case study of the Algonquin Nation of Wolf Lake. Conservation \& Society, 13, 72-83.

Simons, E.L. \& Meyers, D.M. (2001) Folklore and beliefs about the aye aye (Daubentonia madagascariensis). Lemur News, 6, 3528.

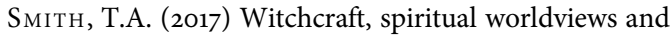
environmental management: rationality and assemblage. Environment and Planning A, 49, 592-611.
SöRLIN, S. (2012) Environmental humanities: why should biologists interested in the environment take the humanities seriously? BioScience, 62, 788-789.

Stambach, A. (2000) The rationality debate revisited. Reviews in Anthropology, 28, 341-351.

St John, F.A., Keane, A.M. \& Milner-Gulland, E.J. (2013) Effective conservation depends upon understanding human behaviour. In Key Topics in Conservation Biology 2 (eds D. W. Macdonald \& K.J. Willis), pp. 344-361. John Wiley \& Sons, Oxford, UK.

Sunseri, T. (1999) Majimaji and the Millennium: Abrahamic sources and the creation of a Tanzanian resistance tradition. History in Africa, 26, 365-378.

The Guardian (2013) Elf lobby blocks Iceland road project. Https:// www.theguardian.com/world/2013/dec/22/elf-lobby-icelandroad-project [accessed 19 May 2017].

Tingle, J. (2012) Snakes in Madagascar's folklore. Https://jleetingle. wordpress.com/2012/12/o4/snakes-in-madagascars-folklore/ [accessed 10 March 2016].

Turvey, S.T., Fernández-Secades, C., Nuñez-Miño, J.M., Hart, T., Martinez, P., Brocca, J.L. \& Young, R.P. (2014) Is local ecological knowledge a useful conservation tool for small mammals in a Caribbean multicultural landscape? Biological Conservation, 169, 189-197.

VerschuUren, B. (2006) An overview of cultural and spiritual values in ecosystem management and conservation strategies. In International Conference on Endogenous Development and Biocultural Diversity, October 2006, Geneva, Switzerland.

VirTANen, P. (2002) The role of customary institutions in the conservation of biodiversity: sacred forests in Mozambique. Environmental Values, 11, 227-241.

Wiley, J.W. (1985) Status and conservation of forest raptors in the West Indies. ICBP Technical Publication, 5, 199-204.

\section{Biographical sketches}

GeOrge Holmes's research focuses primarily on the interaction of protected areas and local communities, particularly contests over the social impacts of conservation, and on the political economy of conservation, including private protected areas. He has conducted extended fieldwork in the Dominican Republic and Chile. Tом Sмiтh's research has included work on environmental education and young people's involvement in conservation in Tanzania and the UK, spiritual beliefs and witchcraft in conservation, abstract notions of environmental value, and urban housing in Kenya. He has also conducted research in the UK on technology and roaming in national parks. CAROLINE WARD is conducting research into changes in protected area governance in Madagascar, and their interaction with ecosystem services and local livelihoods. 